\title{
The W2Plastics Project: Exploring the Limits of Polymer Separation
}

\author{
F. Di Maio ${ }^{*}, 1$, P. Rem ${ }^{1}$, B. $\mathrm{Hu}^{1}$, S. Serranti ${ }^{2}$ and G. Bonifazi ${ }^{2}$
}

\author{
${ }^{I}$ Delft University of Technology, Faculty of Civil Engineering and Geosciences, Section Materials and Environment / \\ Recycling Technology, Stevinweg 1, 2628 CN, The Netherlands \\ ${ }^{2}$ Department of Chemical Engineering Materials \& Environment, Sapienza University of Rome, Via Eudossiana 18, \\ 00184, Rome, Italy
}

\begin{abstract}
The efficient large-scale recycling of plastic waste is of increasing interest from an ecological and economic point of view but it represents a goal that has yet to be achieved by the recycling industry. The W2Plastics project aims at a fundamental change of the present status of plastics recycling by creating a breakthrough technology for the recycling of polyolefin's from complex wastes, i.e., wastes such as Waste from Electric and Electronic Equipment (WEEE), Construction and Demolition Waste (CDW), household waste and Automotive Shredder Residue (ASR). Polyolefin's are a very important family of polymers, constituting more than a third of the total plastics consumption in Europe (EU) and complex wastes provide the vastest, presently unused potential resource of secondary polyolefin's. In spite of that, Polyolefin's (PP, LDPE, HDPE) are the least recycled plastics materials. Only one million ton out of 14 million tons yearly sold in EU is being recycled. Nowadays, Polyolefin recyclers focus mainly on the relatively pure post-industrial or single-product wastes, since these wastes can be made into high-purity product materials by existing and cost-effective process technology. Post-industrial wastes are increasingly exported outside the EU, however, and so the Polyolefin recycling industry and their end-users are forced to look for alternative resources. In principle, post-consumer wastes, such as WEEE, CDW, household waste and ASR provide such a resource. They are a five to ten times larger reservoir of polyolefin's than do post-industrial wastes, but these wastes are also much more complex mixtures of materials and hence much more difficult to recycle. Technologies that are to address these resources need to be extremely powerful, since they must be relatively simple to be cost-effective, but also accurate enough to create high-purity products and able to valorise a substantial fraction of the materials that are present in the waste into useful products of consistent quality in order to be economical. The European FP7 Project: W2Plastics is developing a number of novel concepts, in particular Magnetic Density Separation (MDS) and Ultrasound process and quality control by HyperSpectral Imaging (HSI), into a new technology to recover high-purity polyolefin's from complex wastes at low cost. The unique promise of this new concept derives from its ability to accurately separate many different materials in a single process step, resulting in an environmentally friendly and cheap process.
\end{abstract}

Keywords: Polymer, recycling, magnetic density separation, ultrasounds, hyperspectral.

\section{INTRODUCTION}

The European annual consumption of plastic materials has increased from 24.6 Mt in 1993 to $39.7 \mathrm{Mt}$ in 2003 (nearly half being polyolefins) and it is likely to keep growing, so that Europe is faced with the daunting challenge of managing millions of tons of waste plastics. At the same time, polymer recyclers and manufacturing industries have a problem in buying feed materials and secondary polymers of sufficient volume and consistent quality, as a result of the strong pull of China and India on raw material resources. In addition, the production and use of plastics has a range of environmental impacts because about two $\mathrm{kg}$ oil are needed to produce one $\mathrm{kg}$ plastic.

Today, Polyolefin recyclers focus mainly on the relatively pure post-industrial or single-product wastes, since these wastes can be made into high-purity product materials

*Address correspondence to this author at the Delft University of Technology, Faculty of Civil Engineering and Geosciences, Section Materials and Environment / Recycling Technology, Stevinweg 1, $2628 \mathrm{CN}$, The Netherlands; Tel: +31 1527 83688; Fax: +31 1527 82460;

E-mail: f.dimaio@tudelft.nl by existing and cost-effective process technology. Postindustrial wastes are increasingly exported outside the EU, however, and so the European Polyolefin recycling industry and their end-users are forced to look for alternative resources. In principle, post-consumer wastes, such as Construction and Demolition Waste (CDW), Waste from Electric and Electronic Equipment (WEEE), household waste and Automotive Shredder Residues (ASR) provide such a resource. They are from five to ten times larger reservoir of Polyolefin's than do post-industrial wastes, but these wastes are also much more complex mixtures of materials and hence much more difficult to recycle. For this reason, nowadays just one million out of about 14 million ton (Polyolefins) yearly sold in Europe is recycled. Most of the polymer resources in complex wastes, such as WEEE, household waste and ASR (ACEA: 2.5 to 3 million tonnes as part of 7.5 million tonnes total shredder residue in European (EU17) ASR in 2002), are largely unused. The main reason is the low efficiency of the current separation technologies for the secondary plastics.

Technologies that are to address post-consumer wastes need to be extremely powerful, since they must be relatively 
simple to be cost-effective, but also accurate enough to create high-purity products and able to valorize a substantial fraction of the materials that are present in the waste into useful products of consistent quality in order to be economical. On the other hand, the potential market for such technologies is large.

The European FP7 Project W2Plastics - Magnetic Sorting and Ultrasound Sensor Technologies for Production of High Purity Secondary Polyolefins from Waste aims to develop two novel concepts, Magnetic Density Separation (MDS) and Ultrasound process and quality control, adopting an HyperSpectral Imaging (HSI) based approach, into a new technology to recover high-purity Polyolefin's from complex wastes at low cost. The unique promise of this new concept (which includes new hyperspectral imaging based qualitycontrol logics) derives from its ability to accurately separate many different materials in a single process step, using an environmentally friendly and cheap process fluid. Because of its intrinsic flexibility, this technology can easily be implemented to separate any kind of plastic materials. Taking into consideration that recycling practice shows that a single breakthrough technology takes many years to become available on the market in the absence of infrastructure and related technologies, W2Plastics does not just focus on a single breakthrough technology, but rather considers the entire chain of production and quality control of secondary polyolefins. In order to reach the goals of the project, the scientific and technological objective of W2Plastics project is pursuing the following three main routes:

Route 1. Relating the economic and ecologic value of polyolefin-containing wastes to the properties of the waste and the acceptance strategies, logistics and process technology of the facilities generating them.

Route 2 . Creating an environmentally friendly and costeffective bulk process MDS technology, that can recover high-purity polyolefin products from the float fraction of complex wastes at commercial capacities.

$\underline{\text { Route } 3}$. Developing process control and quality control technology using powerful sensor technologies.

\section{AN OVERVIEW OF W2PLASTICS TECHNOLOGIE IN RESPECT OF "THE STATUS OF THE ART"}

\subsection{The MDS Technology}

In order to produce high-purity granulate from complex streams of post-consumer waste, of a quality comparable to materials presently produced from post-industrial waste, a separation technology is needed that is sensitive to very small differences in the physical properties of the materials. At the same time, in order to be economically and ecologically sound, the process should recover most of the polyolefins into useful products and minimize process residues.

Current available separation technology is mainly based on a accurate identification of the primary plastic contained in a particular item, followed by some type of manual or automated sorting are essential [1]. In the case of plastic bottle sorting, automated selection procedures, commonly based on optical-sensing-techniques (OST) can be applied. They are not so successful because of the different bottles size and shape characteristics. Furthermore the presence of labels, surface contamination, presence of paint and coating, represent an other obstacle in the utilisation of OST. Another wide applied sorting strategy is based on density. Also this approach is not particularly helpful, especially to perform a very strict separation. Most plastics, in fact, are very close in density $\left(\rho_{\mathrm{HDPE}}=0.941 \mathrm{~g} / \mathrm{cm}^{3}, \rho_{\mathrm{MDPE}}=0.926-0.940 \mathrm{~g} / \mathrm{cm}^{3}\right.$, $\rho_{\text {LDPE }}=0.915-0.925 \mathrm{~g} / \mathrm{cm}^{3}, \rho_{\text {LLDPE }}=0.91-0.94 \mathrm{~g} / \mathrm{cm}^{3}, \rho_{\text {PP }}=$ $\left.0.96 \mathrm{~g} / \mathrm{cm}^{3}\right)$. In the case of rigid plastic rigid waste, resulting from electronic parts, a heavy medium separation is usually applied [2]. This can be done by adding a modifier to water or by using tetrabromoethane (TBE). However, this is a costly process and can lead to contamination of the recovered plastic $[2,3]$. Hydrocyclones can represent a good tool to strength density separation efficiency. Hydrocyclones, which use centrifugal force, enhance material wettability. Some of the factors affecting liquid separation of a given plastics material are: i) degree of wettability, ii) variation in density, related to polymeric structure, fillers materials utilised, typologies of pigments, etc., iii) morphological and morphometrical characteristics of plastic particles as they result from comminutionclassification processes, iv) degree of liberation of one polymer in respect of another one or to other non-plastics materials. The presence of air bubbles attached to plastic particles produce different negative effects of specific plastic recovery, that is: i) a reduced wetting of the surface and ii) a floating of the particles due to the fact that the system airplastic flake float in a solution less dense than that of bulk material [4]. Triboelectric separation, which can distinguish between two resins by simply rubbing them against each other, is another sorting strategy currently applied to separate plastics. A triboelectric based separation device sorts materials on the basis of a surface charge transfer phenomenon. When materials are rubbed against each other, one material becomes positively charged, and the other becomes negatively charged or remains neutral. Particles are mixed and contact one another in a rotating drum to allow charging. Materials with a particle size of approximately 2-4 $\mathrm{mm}$ were the highest in both purity and recovery in the triboelectric process [5]. Plastic solid waste can also be sorted by a speed accelerator technique, developed by Result Technology AG (Switzerland). This technique uses a highspeed accelerator to delaminate shredded waste, and the delaminated material is separated by air classification, sieves, and electrostatics [2]. Using X-ray fluorescent (XRF) spectroscopy, different types of flame-retardants (FRs) can be identified. On this basis, MBA Polymers, Inc. has developed a technology that can separate pure resin with FRs $[6,7]$.

W2Plastics is applying the emerging technology called Magnetic Density Separation (MDS) [8] to separate the various types of Polyolefins: polypropylene (PP), low density polyethylene (LDPE) and high density polyethylene (HDPE), from each other and from contaminant materials such as wood, rubbers and minor amounts of metals and foams. MDS technology is potentially very cheap because it separates a complex mixture into many different materials in a single process step, using one and the same liquid. The entire separation is performed as the mixture flows through a channel and segregates in a few seconds into as many different layers as there are products. The water-based 
process liquid is recovered mechanically to the point that only about $5 \mathrm{~kg}$ of liquid remains per ton of de-watered product. Since each $\mathrm{kg}$ of process liquid contains as little as 6 grams of iron oxide (the active material for the separation), most applications of the polyolefin products do not require that such a minor amount of liquid need to be washed from the plastics. Therefore very low costs are associated with the recycling and quality control of the liquid, usually one of the expensive steps in advanced sink-float separations. MDS is also potentially very sensitive to small differences in material density, provided that the turbulence in the liquid can be accurately controlled. Preliminary results obtained with a small MDS laboratory setup have shown that PP could be separated cleanly from PE.

\subsection{The Ultrasounds Technology}

A precise and on-line assessment of the composition of process streams is of the utmost importance for both the recycling and compounder industry in the transition to the recycling of post-consumer wastes. The former needs it to monitor the separation process. The latter demands it for the most accurate (and fast) composition assessment to calibrate the extruders (equipments) and to fulfill customers' requirements as well. Therefore fast on-line assessment is a key point to increase the value of secondary Polyolefin's.

The state-of-the-art analysis of PP or PE concentrates in terms of the concentration of the other Polyolefin as well as non-polyolefin contaminants is by means of hand-sorting and thermal DSC analysis of samples in the laboratory. Other methods are CRYSTAF, Infra-red spectroscopy [9] and TREF [10]. Neither of these methods is suitable and accurate for the required on-line quality assessment and so sensor technology must be developed that is able to quantify the concentration of contaminants and particle size distribution in each of the products.

Ultrasound has proved to be a useful tool in the quality assessment of materials and 4-D imaging of interfaces between solids and liquids. The technology is extremely advanced in geology, navigation and in medical fields. Applications also concern with leak detection, tightness testing, and predictive maintenance, etc. Ultrasound imaging technology has developed very fast into a tool with a high resolution (about $1 \mathrm{~mm}$ pixel width) and a short capture time (less than 0.1 second per frame). The special feature of the technology is that the image clearly shows internal interfaces between solids and liquids with a slightly different speed of sound. Therefore, the technique has the potential to measure both the spatial distribution of solids as well as their shape and material/interface properties. Ultrasound imaging technology uses the pulse-echo technique as in navigation (SONAR) and other applications. The ultrasound arrays transmit ultrasonic sound pulses (also known as sound waves), into the part of interest inside the imaged volume, which can range from industrial parts to organs of human bodies. As soon as the sound waves hit the boundary between materials with different phases they are reflected back to the probe/receiver. These ultrasonic echoes and the time intervals for them to be reflected are recorded. From the time of each echo's return and the known speed of sound, the distances of the different interfaces from the probe/receiver are determined. Then data are processed by inversion algorithms and the distances as well as the intensities of these echoes are displayed, resulting in a two, three or four dimensional image (movie). Best results are obtained in applications where the various materials have a comparable speed of sound, to facilitate a balance of transmission and reflection along with the generation of echoes.

The development beyond the state-of-the-art in ultrasound technology in this project is to design an array and solve the inverse problem of sound travelling through the suspension to create 4D images of the suspension of particles in the MDS channel for the present application. The aim is to interpret the echo into the spatial distribution and brightness of particles. These data can be related to the apparent density, internal speed of sound and surface texture of the particles and therefore to the quality of the feed and the separation.

\subsection{The HyperSpectral Imaging (HSI) Technology}

HyperSpectral Imaging [11] is a fast emerging technology that can be also profitably utilized for the analysis of particulate solid systems in terms of composition and spatial distribution. The technology can be used on-line and is cheap and powerful. HSI was originally developed for remote sensing applications [12] but has found application in such diverse fields as astronomy [13, 14], agriculture [1517], pharmaceuticals [18-20] and medicine [21-24]. In this last years several operative procedures and logics based on such a technology have been developed both at research and application level also in the recycling sector [25] for different waste materials [26, 27].

Hyperspectral cameras are able to deliver a wide spectrum of information on particulate solids streams. Investigated spectral responses are usually those belonging to VIS (400-700 nm) and VIS-NIR (400-1000 $\mathrm{nm}$ and 1000$1700 \mathrm{~nm}$ ) wavelengths ranges; they are usually correlated to particle composition. Together with spectral response other parameters are collected, as particle morphological and morphometrical attributes distribution, spatial and temporal fluctuations of the particle stream, etc.

The development beyond the state-of-the-art will be to interpret the possibilities of HSI in determining the quality of feed and product streams in the recycling of post-consumer waste and translate the collected information into the parameters that are requested by the recycling operation, both in terms of control strategies set up and products quality assessment at the different stages of the processing. As an alternative to hyperspectral imaging, and to make operative comparisons, Dual Energy X-ray sensors are investigated as a means to detect chlorinated or bromated plastics as well as metallic impurities in the feed and separation products.

\section{SCIENTIFIC AND TECHNOLOGY DEVELOPMENTS}

The overall object of the project is to bring about a fundamental change of the status of complex wastes such as CDW, household waste, WEEE, and ASR: from materials that are largely land filled or incinerated to resources of high-value secondary polyolefin's. Therefore relevant progresses have to be made in several research and technology areas in order to realize the above mentioned ambitious object (Fig. 1). In particular, advances beyond the state-of-the-art in sensor and quality control technologies, 


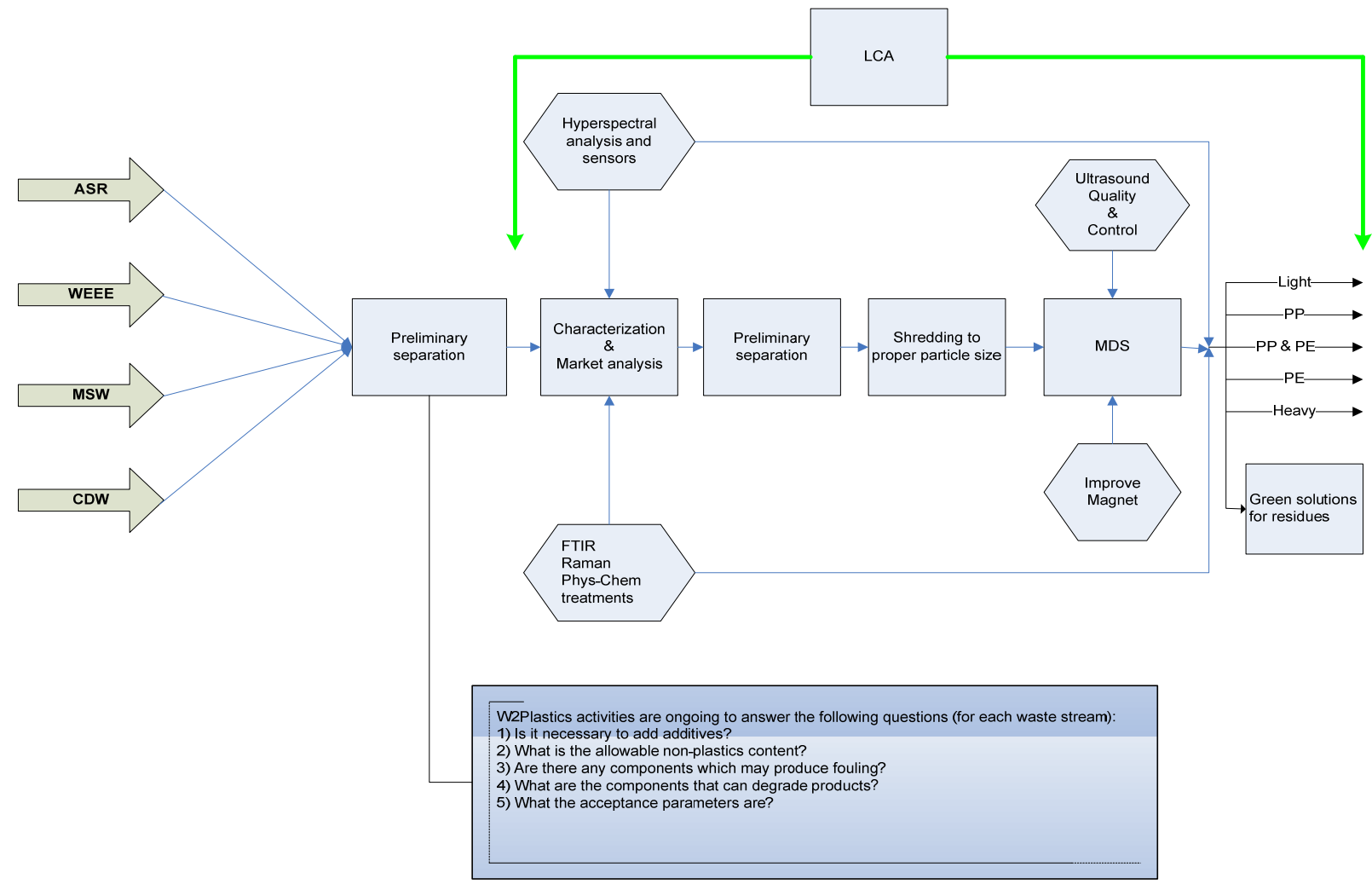

Fig. (1). Flow chart of the activities carried out inside the European FP7 Project W2P - Magnetic Sorting and Ultrasound Sensor Technologies for Production of High Purity Secondary Polyolefins from Waste.

magnetic density separation, process modelling and computing, secondary polymer production, comparative Life Cycle Analysis (LCA) are mandatory to reach the targets of the project.

\subsection{Numerical Simulation of MDS Technology}

Advances in MDS from the W2Plastics project will be developed and implemented in terms of separation accuracy, multi-product separation and separation kinetics. To achieve these ambitious goals, flow geometries especially in separation zone are investigated by using numerical simulation.

The MDS setup, which has been built up, consists of injection zone, laminator, separation zone and product collection zone (Fig. 2). The separation is a complex mix of fluid dynamics, particle-particle interactions and magnetic separation forces. Particles of polymers are easily packed so that poor separation behaviour will be shown. For this reason, the mixture of wetted particles is mixed with the process fluid in a turbulent flow, which disperses the various materials over the cross-section of the channel. However, entering the magnetic separation zone, the fluid must become as laminar as possible in order to let the magnetic forces create the separation without turbulence. Hence, the flow of the process liquid and the movement of the particles are essential for simulation, especially in the separation zone. A model of the separation zone has been done (Fig. 3). By continuously comparing the simulation and experiments, the design of the MDS setup will be optimized. And the simulation must give multiple answers in order to have sufficient flexibility for the elaboration of the final design.

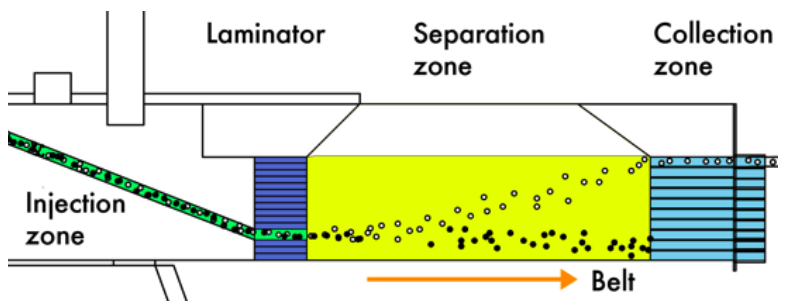

Fig. (2). Medium Density Separation (MDS) setup.

\subsection{Wetting Technology}

A major factor, next to the fluid dynamics, is the entrainment of air bubbles and the absorption of moisture by materials such as wood. Special attention is paid to the wetting process to avoid flotation of particles or variation of material density, which would affect the separation accuracy or introduce contaminants into the polyolefin products. In order to become a practical method for polyolefin separation, MDS technology must reach an accuracy of $10 \mathrm{~kg} / \mathrm{m}^{3}$ at commercially interesting production rates of $5 \mathrm{t} / \mathrm{h}$ or more. Therefore, on the efficiency of the wetting process, the aim is to eliminate air bubbles to less than $1 \%$ of the volume of the flakes. 


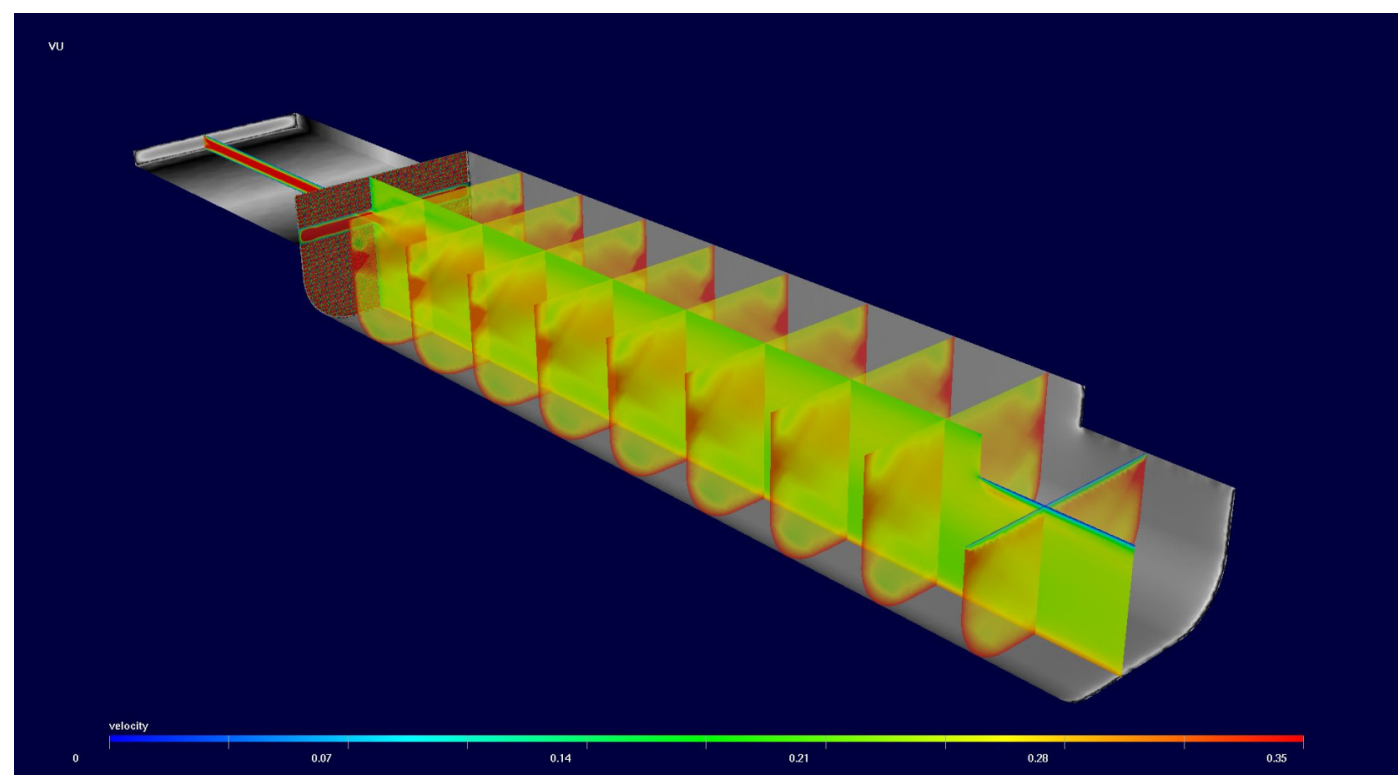

Fig. (3). Simulated separation zone inside the MDS.

Traditional methods for wetting plastic flakes in sinkfloat separation are wet grinding or friction washing. Industrial practices based on these methods show that a significant fraction of the heavy materials still end up in the float fraction. Experiments, in which the shear at the flake surface is increased by means of passing a high speed water flow $(1 \mathrm{~m} / \mathrm{s})$ through a bed of plastics in between screens, show a more efficient removal of air, but such a procedure is difficult to implement as a continuous process. An alternative to mechanical methods is to add surfactants to the process water, such as alcohol. Such additives are able to effectively wet the plastics, but a disadvantage is that surfactants contaminate the process liquid. A new route to wet the surface of hydrophobic materials is by means of contacting with steam or boiling water. In these methods, the air is carried away with the steam and the surface of the particles is completely covered with water. The experiments carried out so far showed that the wettability of most polymers improves slightly by steaming for about 1 minute, but the best wetting results were obtained with immersion in boiling tap water. Shredded plastics were easier to be wetted than virgin polymers. A new wetting process to eliminate air bubbles was developed on the basis of these results that carry a minimal amount of heat and water with the feed to the MDS process liquid.

\subsection{Ultrasounds Technology}

Despite the potential accuracy of MDS, some contamination of the products is unavoidable due to the natural overlapping of density ranges of the different materials. The extent to which this problem occurs depends on the composition of the actual feed material and so it cannot be solved in the design stage. For this reason, a precise and on-line assessment of the composition of process streams will be developed on the basis of ultrasound to allow making the best possible product from a given feedstock. The ultrasound imaging technology needed is beyond the state-of-the-art and aims to interpret the echo from particles suspended in the magnetic fluid into the spatial distribution and brightness of materials, such that differences between the various polyolefins and contaminants can be recognized and through the differences of their spatial distribution can be translated into product qualities. The same ultrasound technology is also crucial to detect obstructions of the flow or sub-optimal splitter settings.

To date the possibility to adapt off-the-shelf medical imaging technology was investigated with an eye towards the real-time requirements for industrial MDS monitoring. It is shown that a medical system can be adapted for monitoring the flowing plastics for particle speeds up to 30 $\mathrm{cm} / \mathrm{s}$. The imaging quality can be quite good under optimum viewing angle conditions, and may then also allow for quantitative through-put analysis (Fig. 4). Moreover the potential of ultrasound for materials characterization from inside the magnetic fluid was investigated through research on wave generation and propagation in wave attenuating media through experiments and 3D acoustic modelling. Using a calibrated measurement setup it has been shown that different polyolefin groups are acoustically distinctive, which is the primary condition for ultrasound quality inspection.

\subsection{HSI Technology}

HSI is a cost-effective emerging technology for the online assessment of particulate product streams. The aim of the project is to develop this technology into a monitoring tool for detecting foreign materials, such as rubber or wood in the input waste as well as in the polyolefin products. For the most ambitious applications, the sensors must be able to recognize materials other than Polyolefins at levels of $1 \%$ and less.

HSI is based on the utilization of an integrated hardware and software architecture able to digitally capture and handle spectra, as an image sequence, as they results along a predefined alignment on a surface sample properly energized. According to the different wavelength of the source and the different spectral sensitivity of the device, different physicalchemical superficial characteristics of the sample can be investigated and analyzed. The hyperspectral imaging 


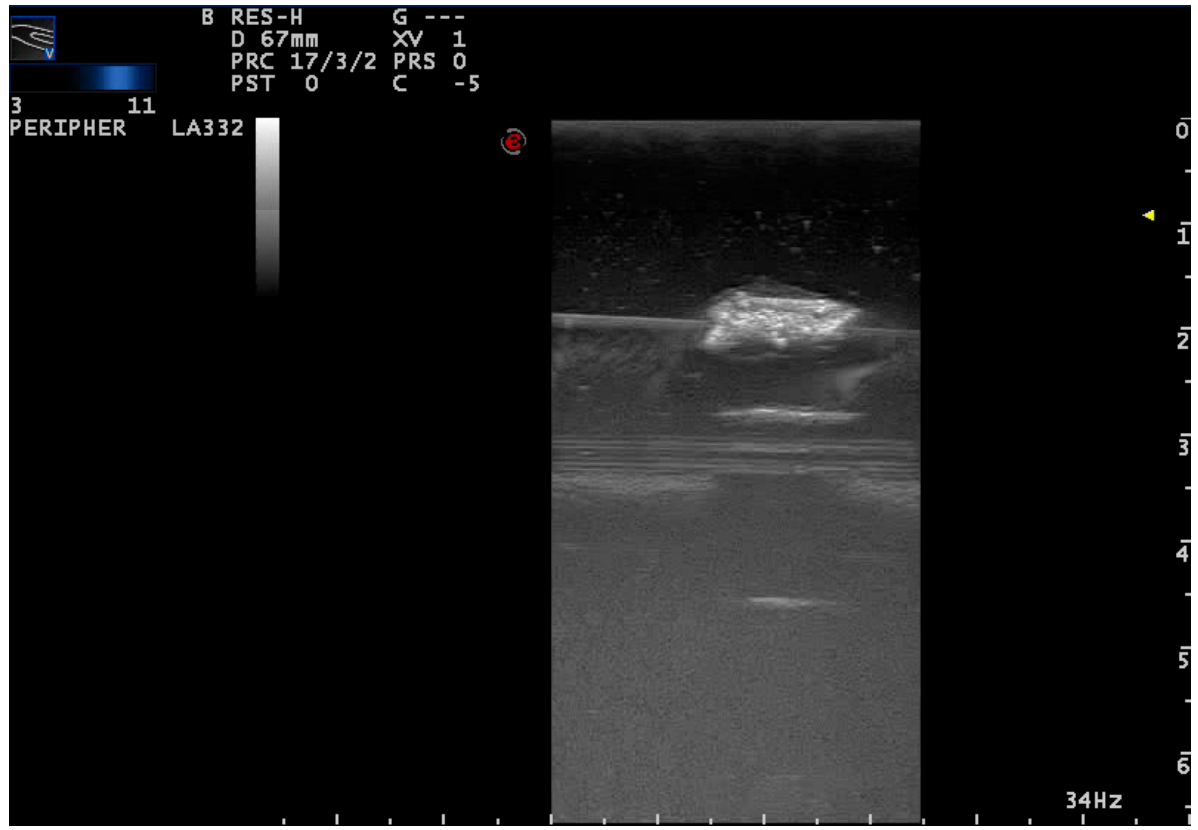

Fig. (4). Example of the potentialities offered by the application of medical ultrasound imaging technology applied to plastics particles identification inside a fluid.

acquisition system adopted in this study is based on the utilization of a device: the ImSpector ${ }^{\mathrm{TM}} \mathrm{V} 10 \mathrm{E}$, belonging to the ImSpector series spectrometers, developed by SpecIm ${ }^{\mathrm{TM}}$ Oy, the system shown in (Fig. 5).

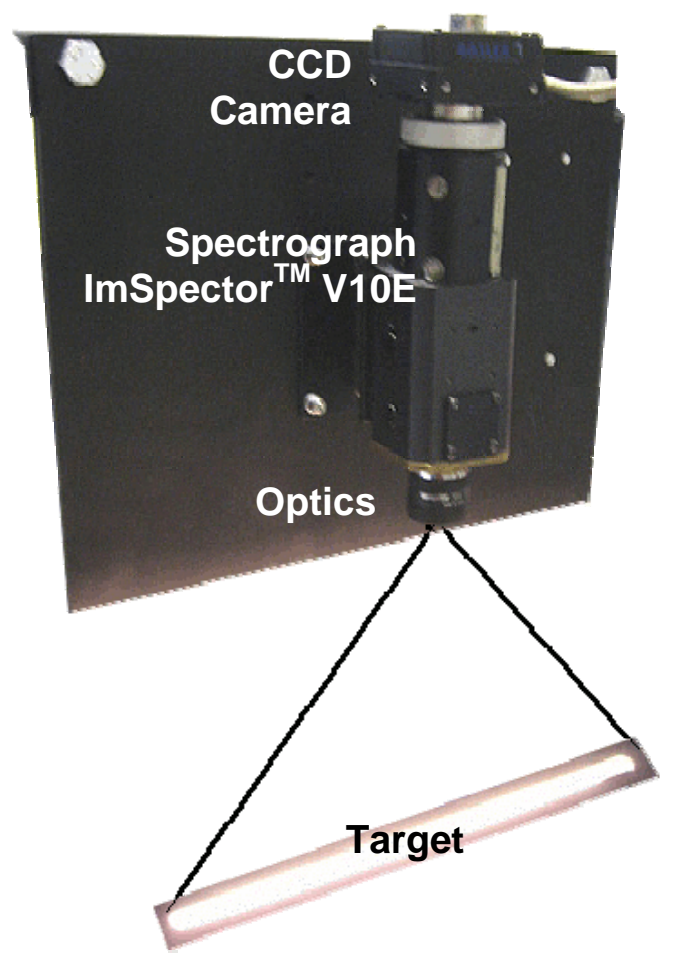

Fig. (5). Hyperspectral Imaging (HSI) based acquisition device to collect secondary plastic particles flow streams spectra.

The ImSpector ${ }^{\mathrm{TM}} \mathrm{V} 10 \mathrm{E}$ operates in the spectral range between $400 \mathrm{~nm}$ and $1000 \mathrm{~nm}$ with a resolution of $2.8 \mathrm{~nm}$. The acquired images are $780 \times 580$ pixel size, corresponding to $6.5 \times 14.2 \mathrm{~mm}$. The spectrograph is constituted by optics based on volume type holographic transmission grating. The grating is used in patented prism-grating-prism construction (PGP element) characterized by high diffraction efficiency, good spectral linearity and it is nearly free of geometrical aberrations due to the on-axis operation principle. A collimated light beam is dispersed at the PGP so that the central wavelength passes symmetrically through the grating and prisms and the short and longer wavelengths are dispersed up and down compared to central wavelength. This results in a minimum deviation from the ideal on-axis condition and minimizes geometrical aberrations both in spatial and spectral axis. The result of acquisition is a digital image where each column represents the discrete spectrum values of the corresponding element of the sensitive linear array. Such an architecture allows, with a "simple" arrangement of the detection device ("scan line" perpendicular to the moving direction of the objects) to realize a full and continuous control. Line lighting, as energizing source with uniform spatial distribution, was thus used.

\subsection{Characterization and Tests of Plastics}

Not all polyolefin-containing waste streams have the same economic value for the W2Plastics route. In particular, the ultimate purity of products from the process and the amount of residue produced depend on the particular composition of the input waste mixture. A transparent relation between value and composition will help suppliers of the polyolefin-containing waste to optimize their own process and acceptance strategies in line with the eventual valorisation of the Polyolefins. One of the objectives of the project is to make sure that complex wastes of suitable qualities become widely available and standards and quality assessment technology are developed to determine whether a given batch of material can be processed into high-value polyolefin products or not. 


\subsection{Treatments of Process Residue}

In order to make the project robust with respect to the a priori uncertain success of the research, separate subprojects are to cope with problems arising from process residues and varying polymer quality. As an example, a very robust alternative process is being investigated for minor fractions of polyolefins that cannot be further processed by the W2Plastics route. At the downstream side, the effect of additives to stabilize the quality and increase the economic value of polymer products is also being investigated. One the main reasons for starting the project is to lighten the ecological burden of polymers, while at the same time producing economic benefit from the complex waste streams. In order to balance the economy and ecology of the W2Plastics route, all data generated by the project are analyzed by Life Cycle Impact assessment.

\section{PROJECT ORGANIZATION}

The goals of the W2Plastics project are to be achieved by a large group of interactive academic and industrial partners, working together in 12 different work packages (WPs). The structure of each WP and the relationship/interaction (input $\leftrightarrow$ output) are defined according to the different research strategies and technological implementation outlined in (Fig. 6). Results from the different work packages are integrated in two different ways. Data on materials and processes are exchanged as usual, by means of a project website and meetings. Equipment and software, on the other hand, are brought together and tested in a technology platform. WP10 was specifically addressed to fulfil this goal.
Plastics streams from different sources and locations will be characterized by Recycling Avenue (The Netherlands), which will collect all relevant data about the physical properties of polyolefin-containing waste streams and also data on the processes and waste acceptance strategies of primary waste processors.

The application possibilities of high purity secondary polyolefins will be investigated by the Budapest University of Technology and Economics (Hungary), which will carry out analysis of the recycled polyolefins and design modification methods for improving their properties and quality. The same group will also develop efficient stabilizer combinations for overcoming the stability deficiencies. The magneto-hydrostatic separation, a mix of fluid dynamics, particle-particle interactions and magnetic separation forces will be investigated both experimentally and numerically, by Delft University of Technology (The Netherlands) and the Centro Nacional de Supercomputación (Spain). The same groups, with the help of Oldelft B.V. (The Netherlands), will also develop the ultrasound imaging technology for process control. Quality control methods, both for the input waste and for the polyolefin products, will be evaluated, including methods on the basis of HSI technology developed by $L a$ Sapienza - Università di Roma (Italy) and DV (Iyaly). One of the W2Plastics project' goal is to realize a recycling process which is fully environmental friendly. Green solutions for process residues will be investigated by Transylvania University of Brasov (Romania), while a Life Cycle Assessments led by Technical University of Denmark (Denmark) will ensure assessment and documentation of the environmental improvement from the new W2Plastics

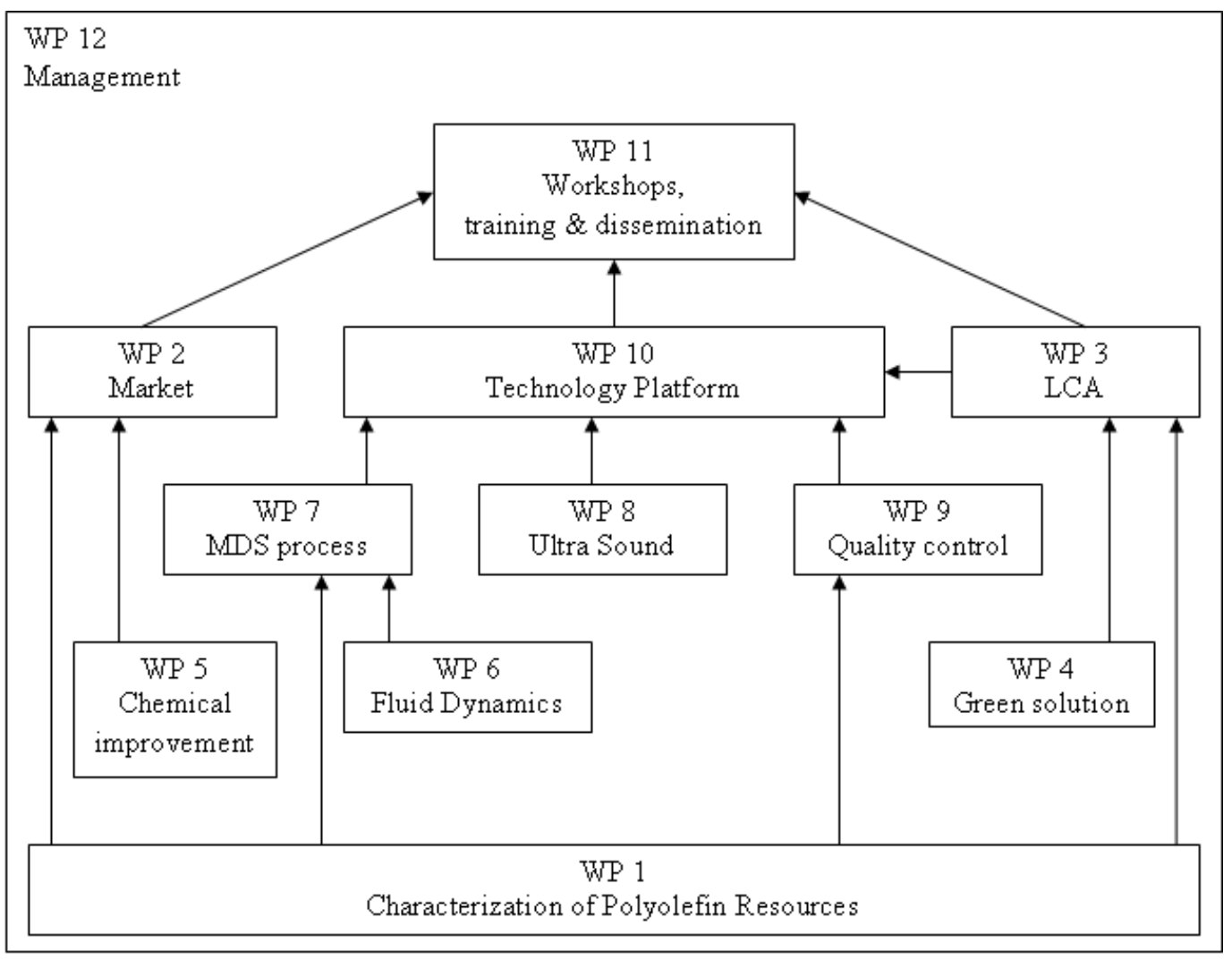

Fig. (6). W2P workpackages architecture and synthetic description. 
technology, in accordance with the philosophy of the European WFD [28, 29] and the ISO 14040/14044 guidelines [30, 31]. The pilot infrastructure created at $A K G$ Polymers (The Netherlands) will contribute to the main goal of the project by transferring the technologies and information needed for the production of high-purity polyolefin's from complex waste to the partner industries. In particular the technology platform that will be created at AKG will allow the technologies developed in other WP's to be fully tested in an industrial environment.

\section{POTENTIAL IMPACT}

\subsection{Strategic Impact}

Despite the fact that polyolefins require a substantial amount of fossil fuels for their production, the materials, once formed, can be a very light and efficient solution for many structural applications. Of all bulk materials used for the production of consumer goods, plastics, in particular Polyolefin's (PE and PP), show the strongest growth rate. Technologies that prevent these materials from ending up as a waste and create economic activity by recycling them have, therefore, a significant social, economic and ecological impact. Turning polyolefin waste back into high purity products has the advantage to keep the benefits of the material while reducing the need for oil. Such technologies provide a strategic advantage in a world in which the regional availability of raw materials and oil is becoming a limitation to economic growth. In addition to the direct environmental and social impact, the technology of W2Plastics is useful in other fields of raw materials, and has spin-offs particularly in heavy plastics, metals and minerals purification.

\subsection{Economic Impact}

The cost-effective production of high-quality secondary polyolefin's from complex wastes, such as ASR, household waste and WEEE has the potential to provide an alternative for 5 to 10 million tonnes of primary polyolefin's in Europe per year, the precise amount depending on the characteristics of the input waste that can economically be recycled under given circumstances (thick, rigid plastics being more easily recyclable than foils). Actual data on the production and recycling of polyolefin's suggest a 30 to $70 \mathrm{MJ}$ gain for every $\mathrm{kg}$ of recycled polyolefin as opposed to its use as an energy carrier or land filling, respectively. Consequently, the direct benefit of replacing 5 million tonnes of primary polyolefin's by high-grade recycled ones is of the order of $250 \mathrm{PJ}$, or, since the energy in producing polyolefin's is generated from oil, about 15 million tonnes of $\mathrm{CO} 2$. This is a considerable amount, even on the scale of the European Union. Indirectly, the benefit is even greater, since complex wastes such as ASR and WEEE typically contain several percents of non-ferrous metals (such as copper and aluminium) and the recycling of the bulk plastics implies and triggers the concentration of these metals into recyclable fractions of light and heavy non-ferrous alloys beyond current levels.

On the socio-economic level, the recycling of millions of tonnes of polyolefin's from complex wastes creates a considerable economic activity. Companies producing secondary polyolefin granules from post-industrial waste typically have an output capacity of 25,000 tons per year and about 25 employees. These companies presently have a difficulty in buying suitable feed, because of the strong pull of large developing economies in the Far East. The amount of recyclable rigid polyolefin's from complex post-consumer wastes is more than five times the amount of post-industrial waste and therefore presents an economic potential of more than 4 billion euro per year and approximately ten thousand jobs (including concentration, recovery and compounding). Strategically, a cost-effective recycling technology for polyolefin's provides a steady regional supply of raw materials for the production of consumer goods (e.g. cars).

\subsection{Ecological Impact}

In Europe, about 40 million tons of plastics are produced every year and most likely the production will keep growing. Currently, plastics production grows at an even faster rate than economy does. Nearly half of the plastics production comes from PE and PP, both of which are causing a range of environmental impacts. Firstly, plastics production requires significant quantities of resources, both as a raw material (oil) and to power the production process (about two kg oil are necessary to produce $1 \mathrm{~kg}$ PE or PP). Secondly plastic materials when released into the environment can also be an unpleasant view and harmful to ecosystems. Moreover plastics debris does not degrade in the environment; instead it tends to accumulate, creating long-term environmental problems. By increasing the PE-PP recycling rate $\mathrm{W} 2$ Plastics will promote a more rational use of resources and will contribute to achieve the European target of reducing the CO2 emissions of $20 \%$ by the end of 2020, hence contributing to reduce the adverse environmental impacts of plastic production.

\subsection{Technological Spin-Off}

W2Plastics is a spin-off from earlier research and development of MDS technology in non-ferrous metals purification, which led to a successful pilot implementation for the high grade purification of fine aluminium scrap in Belgium in November of 2006 and a first large industrial application early this year. Polyolefin purification is the most challenging of all raw materials separations and results in this field will undoubtedly lead to breakthroughs in the recovery and purification of other plastics (e.g. bottle to bottle PET), metals and minerals.

\section{EXPLOITATION}

It is expected that the set-up of the technology platform in combination with the philosophy of the project, to cover all relevant technologies for the processing, process control and quality control, as well as pre- and post-processing, will allow quick implementation of the innovations all over Europe, once the technology proves successful.

\section{ACKNOWLEDGEMENTS}

The project is realized thanks to the financial support of the European Commission in the framework of the FP7 Collaborative project "Magnetic Sorting and Ultrasound Sensor Technologies for Production of High Purity Secondary Polyolefins from Waste (W2Plastics)". Grant Agreement No. 212782. 


\section{REFERENCES}

[1] S. M. Al-Salem, P. Lettieri and J. Baeyens, "Recycling and recovery routes of plastics solid waste (PSW): A review", Waste Manag., vol. 29, pp. 2625-2643, December 2009.

[2] H. Kang and J. M. Schoenung, "Electronic waste recycling: a review of U.S. infrastructure and technology options", Resour. Conserv. Recycl., vol. 45, no. 4, pp. 368-400, March 2005.

[3] H. M.Veit, C. Pereira and A. M. Bernardes, "Using mechanical processing in recycling printed wiring board. J. Minerals Metals Mater. Soc., vol. 54, no. 6, pp. 45-47, January 2002.

[4] American Plastics Council (APC), "Development of hydrocyclones for use in plastic recycling. Technical paper", 1999.

[5] C. Xiao, A. Laurence and M. B. Biddle, "Electrostatic separation and recovery of mixed plastics. In: Society of Plastics Engineers (SPE) Annual Recycling Conference (ARC), Dearborn, Michigan (US), 1999.

[6] S. Toloken, "Computers, plastics don't mix well". In: Waste news; June 1st. Available at: http://www.wasterecyclingnews.com/arcs how, 1998.

[7] American Plastics Council (APC), "An industry full of potential: ten facts to know about plastics from consumer electronics". Technical paper, 2003.

[8] E.J. Bakker, P.C. Rem, N. Fraunholcz, "Upgrading mixed polyolefin waste with magnetic density separation", Waste Management, vol. 29, no. 5, pp. 1712-1717, June 2009.

[9] L. Verdurmen-Noel, L. Baldo, S. Bremmers, "SEC-FTIR characterization of semi-crystalline HDPE and PP", Polymer, vol. 42, no. 13, pp. 5523-5529, July 2000.

[10] N. Samoth, S. Tantayanon, V. Tangpasuthadol and K. Phalakornkul, "Polyethylene Fractionation by Modified Temperature Rising Elution Fractionation Technique". Proceeding of the 8th Polymers for Advanced Technologies International Symposium. Budapest, Hungary, 2005.

[11] G. Bonifazi and S. Serranti, "Hyperspectral Imaging Based Techniques in Particles and Particulate Solids Systems Characterization". The $5^{\text {th }}$ International Conference for Conveying and Handling of Particulate Solids: CHoPS-05, Sorrento, Italy, 2006.

[12] A. F. H. Goetz, G. Vane, T. E. Solomon and B. N. Rock, "Imaging spectrometry for earth remote sensing", Science, vol. 228, pp. 1147-1153, September 1985.

[13] E. Hege, D. O'Connell, W. Johnson, S. Basty and E. Dereniak, "Hyperspectral imaging for astronomy and space surveillance", Proceedings of the SPIE, 5159, 2003, pp. 380-391.

[14] K. S. Wood, A. M. Gulian, G. G. Fritz and D. Van Vechten, "A QVD detector for focal plane hyperspectral imaging". Astronomy. Bull. Am. Astronom. Soc., vol. 34, pp. 12-41, January 2002.

[15] S. Monteiro, Y. Minekawa, Y. Kosugi, T. Akazawa and K. Oda, "Prediction of sweetness and amino acid content in soybean crops from hyperspectral imagery", ISPRS J. Photogramm. Remote Sens., vol. 62 , no. 1, pp. 2-12, January 2007.

[16] V. Smail, A. Fritz and D. Wetzel, "Chemical imaging of intact seeds with NIR focal plane array assists plant breeding", Vib. Spectrosc., vol. 42, no. 2, pp. 215-221, February 2006.
[17] Y. Uno, S. Prasher, R. Lacroix, P. Goel, Y. Karimi and A. Viau, "Artificial neural networks to predict corn yield from Compact Airborne Spectrographic Imager data". Comput. Electron. Agric., vol. 47 , no. 2 , pp. 149-161, January 2005.

[18] R. C. Lyon, D. S. Lester, E. N. Lewis, E. Lee, L. X. Yu and E. H. Jefferson, "Near-infrared spectral imaging for quality assurance of pharmaceutical products: analysis of tablets to assess powder blend homogeneity", AAPS Pharm. Sci. Technol., vol. 3, no. 3, pp. 1-7, January 2002.

[19] O. Rodionova, L. Houmøller, A. Pomerantsev, P. Geladi, J. Burger, V. Dorofeyev, "NIR spectrometry for counterfeit drug detection: a feasibility study", Anal. Chim. Acta, vol. 549, no. 1-2, pp. 151-158, January 2005.

[20] Y. Roggo, A. Edmond, P. Chalus and M. Ulmschneider, "Infrared hyperspectral imaging for qualitative analysis of pharmaceutical solid forms", Anal. Chim. Acta, vol. 535, no. 1-2, pp. 79-87, January 2005.

[21] D. Ferris, R. Lawhead, E. Dickman, N. Holtzapple, J. Miller and S. Grogan, "Multimodal hyperspectral imaging for the non invasive diagnosis of cervical neoplasia", J. Lower Genital Tract Dis., vol. 5, no. 2, pp. 65-72, January 2001.

[22] D. Kellicut, J. Weiswasser, S. Arora, J. Freeman, R. Lew and C. Shuman, "Emerging technology: hyperspectral imaging", Perspectives Vascular Surg. Endovasc. Ther., vol. 16, no. 1, pp. 53-57, January 2004

[23] G. Zheng, Y. Chen, X. Intes, B. Chance and J. D. Glickson, "Contrast-enhanced near-infrared (NIR) optical imaging for subsurface cancer detection", J. Porphyrins Phthalocyanines, vol. 8, no. 9, pp. 1106-1117, December 2004.

[24] A. A. Gowen, C. P. O'Donnel, P. J. Cullen, G. Downey and J. M. Frias, "Hyperspectral imaging - an merging process analytical tool for food quality and safety control", Trends Food Sci. Technol., vol. 18, pp. 590-598, April 2007

[25] S. Serranti and G. Bonifazi, "Solid waste materials characterization and recognition by hyperspectral imaging based logics", The $2^{\text {nd }}$ Int. Symposium MBT 2007: Mechanical Biological Treatment and Automatic Sorting of Municipal Solid Waste, pp. 326-336, 2007.

[26] G. Bonifazi and S. Serranti, "Imaging spectroscopy based strategies for ceramic glass contaminants removal in glass recycling", Int. $J$. Waste Manage., vol. 26, pp. 627-639, June 2006.

[27] G. Bonifazi and S. Serranti "Hyperspectral Imaging Based Techniques in Fluff Sorting". The $21^{\text {st }}$ International Conference on Solid Waste Technology and Management: ICSWM 2006, pp. 740747. March 26-29, Philadelphia, PA, USA.

[28] S. A. Sanaee and M. Bakker, "Ultrasound for monitoring and quality inspection in MDS plastics recycling", ISWA-APESB, Lisbon, Portugal, 2009

[29] Directive 2008/98/ec of the European Parliament and of the Council, 19 November 2008.

[30] ISO 14040:2006: Environmental management -Life cycle assessment - Principles and framework.

[31] ISO 14044:2006: Environmental management - Life cycle assessment - Requirements and guidelines. 